PROXIMITY AND LINKAGES AMONG COALITION PARTICIPANTS

\title{
A NEW VOTING POWER
} MEASURE APPLIED TO THE INTERNATIONAL MONETARY FUND

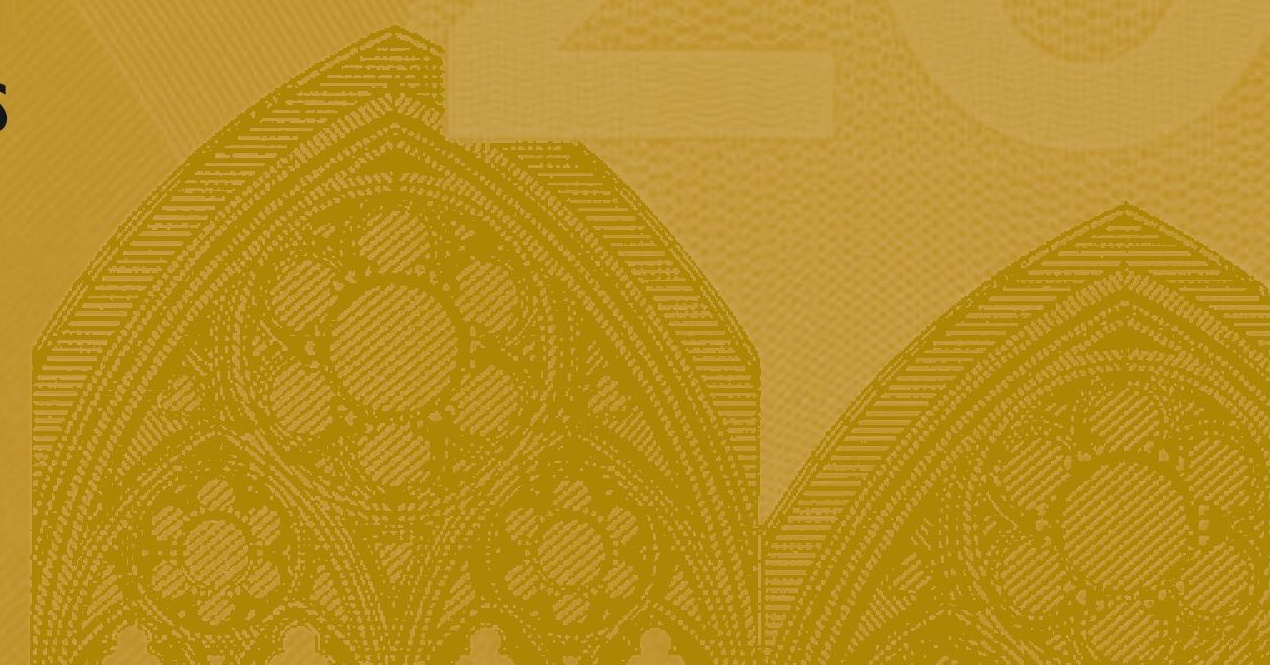

by Julien Reynaud, Christian Thimann and Lukasz Gatarek 


\title{
PROXIMITY AND LINKAGES AMONG COALITION PARTICIPANTS
}

\section{A NEW VOTING POWER MEASURE APPLIED TO THE INTERNATIONAL MONETARY FUND'}

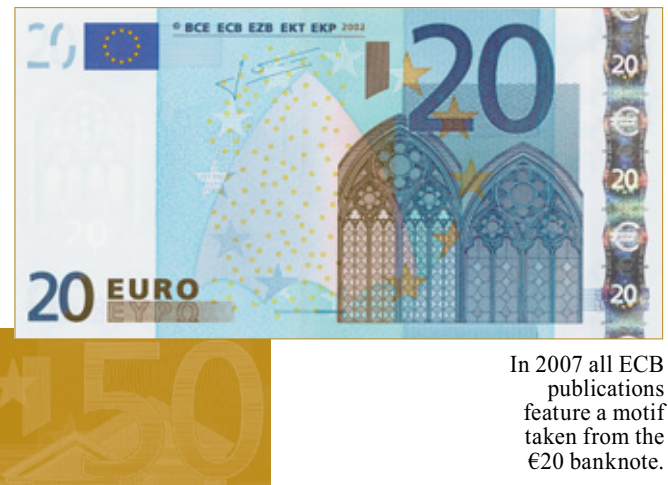

\author{
by Julien Reynaud², \\ Christian Thimann ${ }^{3}$ \\ and Lukasz Gatarek ${ }^{4}$
}

This paper can be downloaded without charge from http://www.ecb.europa.eu or from the Social Science Research Network electronic library at http://ssrn.com/abstract_id=1015273.

I We are grateful to Jeanne Hagenbach, Cuong Le Van, Fabien Lange, to anonymous referees as well as seminar participants at University of Paris I and European Central Bank. The views expressed in this paper are those of the authors. 2 Corresponding author: European Central Bank, Kaiserstrasse 29, D-603II Frankfurt am Main, Germany; e-mail: julien.reynaud@ecb.int, and University Paris I Panthéon-Sorbonne, MSE I06-II2 Bd de l'Hôpital, 75647 Paris cedex 13, France; 
ㄷ European Central Bank, 2007

\section{Address}

Kaiserstrasse 29

60311 Frankfurt am Main, Germany

Postal address

Postfach 160319

60066 Frankfurt am Main, Germany

Telephone

+496913440

\section{Website}

http://www.ecb.europa.eu

\section{Fax}

+496913446000

Telex

411144 ecb d

All rights reserved.

Any reproduction, publication and reprint in the form of a different publication, whether printed or produced electronically, in whole or in part, is permitted only with the explicit written authorisation of the ECB or the author(s).

The views expressed in this paper do not necessarily reflect those of the European Central Bank.

The statement of purpose for the ECB Working Paper Series is available from the ECB website, http://www.ecb.europa. eu/pub/scientific/wps/date/html/index. en.html

ISSN 1561-0810 (print)

ISSN 1725-2806 (online) 


\section{CONTENTS}

Abstract

Non-technical summary

1 Introduction

2 Voting power methodology

2.1 Key terminology

2.2 The Banzhaf index

2.3 Distribution of powers and stability of coalitions in the Banzhaf index

2.4 Capturing linkages in coalition building and departing from the critical voters

3 An index of proximity

4 Applications to the IMF EB

4.1 Applications of the Banzhaf index to the IMF

4.2 Applications of the proximity index

5 Conclusions

Bibliography

\section{Annexes}

A Decision process at the International Monetary Fund

B Determinants of coalition building in the international financial institutions 


\begin{abstract}
Voting power methodology offers insights to understand coalition building in collective decision making. Using cooperative game theory, Banzhaf (1965) developed an index to capture the numerical importance of voters in coalition building. This voting power index is still widely used today in applications to international politics. Yet, it assumes that voters are symmetric and focuses on particular voters only. This paper proposes a new measure of voting power which account for the numerical proximity between voters by capturing how often they appear in winning coalitions together. The index is also developed to account for the relative importance of coalitions and the relative linkages among coalition participants. We present an application to the governance structure of the International Monetary Fund, with linkages being represented by bilateral trade between voters. The results are able to explain several important features of the functioning of this particular voting body, and may be useful for other applications of international politics.
\end{abstract}

Key words: voting power, coalition building, International Monetary Fund

JEL codes: C71, F33 


\section{Non-technical summary}

International policy analysis makes frequent use of voting power indices to explain decision making in international fora, such as the International Monetary Fund, the World Bank and also the European Union. In such contexts, the classical voting power indices - developed first by Shapley and Shubik (1954) and Banzhaf (1965) remain used today and provide indeed helpful insights into the de facto distribution of power that can potentially deviate quite significantly from the notional distribution of voting shares. This is so because depending on the number of voting members, the majority threshold applied and the individual weights of the members, the latter's actual ability to bring together coalitions required to reach the majority threshold can vary significantly from voter to voter.

The classical power indices, however, assume that voters are symmetric, namely that ex ante voters are neutral with regard to the choice of partners for a coalition. Moreover, they focus on critical voters, i.e. the pivotal voters that can turn a losing coalition into a winning one. Yet, in practice, the assumption of symmetry among voters does not hold, in particular not in contexts where coalition building is involved. Indeed, the very notion of coalition refers to the principle of commonly shared interests between voters. Moreover, coalition building is a process that involves all coalition participants. Accordingly, a more realistic assumption is to attribute power not only to one, or a few critical voters, but to all coalition members.

To address these limitations, this paper proposes a new measure of voting power, namely: 'numerical proximity'. While standard voting power indices provide no information on the proximity between voters, such proximity is an important determinant of coalition building. We introduce therefore this measure into a Banzhaf framework - to develop both a bilateral and normalized index - as well as the notion of linkages to capture the principle of commonly shared interests between voters.

Moreover, we consider decision making at the International Monetary Fund, which is currently reviewing its governance, as a numerical example. We apply our index to the countries and constituencies represented at the Fund's Executive Board, with linkages being proxied by bilateral trade between voters. Our numerical results are able to explain several important features of IMF Executive Board functioning, and illustrate perhaps more realistically the power of individual countries. Finally, we are also able to shed light on some possible changes in the structure of the Executive Board, for example those resulting from a merger of chairs held by some European countries. 


\section{Introduction}

Collective decision making is an everyday phenomenon. In some situations formal voting procedures exist, in other situations decisions are made by consensus. Thresholds are most often simple majorities, but higher thresholds can exist for far-reaching decisions. Sometimes, the votes of individuals are weighted, in other contexts one person carries one vote. Despite many difference in setup, most of these situations have one element in common, namely that a single person, group, party or constituency alone does not hold a majority; hence, coalitions are necessary to reach the required majority and take decisions.

Political economy theory, through cooperative game analysis, offers insights to understand coalition building. A first insight is that the notional size of a constituency (individual, country or group) can differ from its effective weight in the decision process. Theory therefore distinguishes between the former, also called voting share, and the latter, also called voting power. Voting power can be larger or smaller than the notional voting share, and the difference depends on how important a single constituency is in the overall context of coalition building. This insight into voting power is well-known in the context of domestic politics. Suppose for example that there are three parties, Red, Rose and Green, in a Parliament of 100 seats, with the first two having 49 seats, and the Green party having 2 seats. If a majority of $51 \%$ is needed, each party needs a coalition with one of the other parties to win the vote. All the parties are therefore equally critical ${ }^{1}$ in terms of their capacity to build a majority coalition. Hence, the voting power of the three parties is equal, at $33.3 \%$. For the larger parties, voting power is lower than their notional weights and the contrary holds true for the smallest party.

A second insight from coalition theory is that voting power depends on the structure of the decision-making body. Again, in the example of a national Parliament, suppose the Rose and Green parties form a new party. This new party would have a majority of $51 \%$ and therefore a voting power of $100 \%$ as no other party would be needed for a majority. Hence, the new party's voting power exceeds that of its constituting members, and the voting power of Red would be zero.

The usefulness of formalised voting power indices, which map notional voting shares into voting power weights and take due account of the majority threshold as well as the number and size of other voters, has been widely recognized. The indices that are most widely used so far were developed by Banzhaf (1965), probably the most prominent index still today, and Shapley and Shubik (1954). Useful as they are, they include two assumptions that remain problematic: first, they treat voters as symmetric, meaning that every voter is assumed to be willing to enter

1 A critical/pivotal voter is a voter that, by adding its support, can turn a losing coalition into a winning one. 
into a coalition with any other voter, and that ex ante voters are neutral with regard to the choice of partners for a coalition. The second shortcoming is that they focus on a particular kind of voter, namely the so-called critical or pivotal voter. Roughly speaking, in the spirit of the Banzhaf index, voters are getting together and start building coalitions until they reach the majority threshold. The last voter is therefore considered as pivotal since it can turn a loosing coalition into a winning one and should be therefore rewarded for that.

These assumptions are at odds since coalitions are more likely between voters, parties or countries that are in some sense closer to another. The very notion of coalition implies the principle of commonly shared interests. Gupta (2003) argues that these shared interests may vary over time and across members, but their purpose is to create a certain degree of linkages, that do not necessarily involve a formal commitment or a commonality of purposes among members of the coalition.

This paper proposes to introduce a new measure of voting power: The numerical proximity, which captures how often individual voters appear in a winning coalition together according to the setup of the game: the allocation of votes, the number of players and the majority rule. The index produces a bilateral measure accounting for the frequency voters may be able to build winning coalition together within a Banzhaf framework that can be normalized to account for the times a voter allows potential allies to form a winning coalition with him. This set-up permits to introduce linkages on top of the numerical proximity: Voters are able to favour, in accordance to their bilateral linkages, a particular winning coalition, when a voter, with whom linkages are relatively strong, appears in the coalition. While in classical power indices voters are willing to share coalition because they may be winning ones, our set-up introduces the fact that voters may favour particular winning coalitions because they have relatively stronger linkages with others coalitions participants according to their numerical proximity. In other words, while the normalized Banzhaf index measures the times a voter is pivotal, the normalized proximity index measures which voters permit (more or less) to the latter to be critical.

We present in this paper an application to the governance structure of the International Monetary Fund and apply our index to the countries and constituencies represented at the Fund's Executive Board. IMF quotas are the principal issue in IMF governance because quotas are central for many aspects of the IMF. A country's quota directly translates into voting rights because the number of votes a country has in the Fund is based primarily on the size of its quota. In addition, a member's quota fixes how much that country may be called upon to lend to other members through the Fund. Finally, it also determines how much a member can borrow from the Fund. This triple role implies that proximity and linkages between voters are 
strategic elements when it comes to voting since the action of voting in the IMF includes the notion of an agreement to (financially) support another member country. For this reason, we use bilateral trade as an indicator reflecting the importance of country relationships. Ceteris paribus, countries that trade more intensively with each other will more likely enter into a coalition at the level of international economic policy. The results of our computations confirm that the United States is an important voter in the IMF. Moreover, this application permits to illustrate the numerical proximity between voters and explain several important features of IMF Executive Board functioning, and more broadly of international politics.

The remainder of this paper is organised as follows. In section 2, we briefly review the definition of voting power indices presenting the most widely used index, namely the Banzhaf index, and present recent research that has tried to capture usual criticisms towards classical power indices. In section 3, we introduce the proximity index and apply it to the IMF Executive Board as a laboratory and discuss our results in section 4. Section 5 concludes.

\section{Voting power methodology}

Voting power methodology is a valuable tool for policy analysis because it captures numerically the distribution of power in collective decision-making processes. Its usefulness is twofold: first, it reveals a distribution of effective power between voters, which can be quite different from the notional distribution of voting shares and which is more relevant in understanding the effective decision-making. Second, voting power analysis can quantify the impact of changes in voting procedures on the voting power of individual or groups of voters. This allows assessing the implications of procedural or institutional changes on the overall voting body.

The latter element was particularly prominent in assessing the consequences on the EU's and ECB's internal voting rules as a result of the enlargement rounds (see among others Kirman et al., 1995; Laruelle and Widgren, 1997; Steunenberg et al., 1999; Baldwin et al., 2000 and Leech, 2001). In this respect, by comparing notional share with effective powers given to voters, voting power indices allow to evaluate the fairness of voting rules and provide positive as well as normative tools in understanding the practices and outcomes by voting bodies.

Following the seminal works by Penrose (1946), Shapley and Shubik (1954) and Banzhaf (1965), most of the work over the subsequent two decades was devoted to the refinement of indices.

Before turning to more recent developments and the description of our new index, we first lay down some basic notations and definitions, and describe the most frequently used index developed by Banzhaf (1965). 


\subsection{Key terminology}

Formally a voting body can be represented as a set $N$, which contains the $n$ voters in the voting body, with $N=\{1,2, \ldots, n\}$ representing the set of voters. Let the set $W$ include all winning subsets of $N$. Three reasonable restrictions are made (Straffin 1978): first, $W$ contains at least one voter, i.e. the empty set of members cannot ensure acceptance. Second, the entire set of voters $N$ ensure acceptance. Third, if $S$ and $T$ are subsets of $N$, with $S \in W$ and $S \subset T$ then $T \in W$. This implies that if $S$ can ensure acceptance and $T$ contains all the members of $S$, then $T$ can also ensure acceptance. These sets refer then here as at least one voter or a group of voters, i.e. a coalition. Hence the total number of possible subsets is $2^{n}$.

If these three conditions are satisfied, a simple game is then defined as an $n$-person game consisting of a pair (N, W) (Von Neumann and Morgenstern, 1944) for which the characteristic function $v$ for a coalition $S$ indicates the value of $S: v(S)=1$ if $S$ is winning and $v(S)=0$ otherwise. In many voting bodies, voters may have weights, represented by their voting share. For example, at the IMF the Executive Directors have voting shares determined by the sum of the quotas of the countries they represent, the quota share being largely determined by a country's economic weight relative to that of other IMF members. Formally, the voting weights for $N$ with a specified vote threshold $q$ are denoted as $\left[q_{1} ; w_{1}, w_{2}, \ldots, w_{n}\right]$. Therefore, $v(S)=1$ iff $S \in W \Leftrightarrow$ $\sum_{i \in S} w_{i} \geq q$, otherwise $v(S)=0$.

A voter $i$ is said to be critical when she has a negative swing in a coalition $S$ if $v(S)=1$, but $v(S-\{i\})=0$. In other words, if voter $i$ withdraws her support, she can turn a winning coalition into a losing one. In this spirit, the classical power indices focus on these critical voters with different types of winning coalitions. First, the largest possible group of winning coalitions is the entire set $W$. We define two subsets of $W$ (Pajala et alii, 2002): The set of minimal winning coalitions $M W C$, and the set of strictly minimal winning coalitions $S M W C$. In a minimal winning coalition there is at least one critical voter; in a strictly minimal winning coalition all voters are critical. This means that in a collation of the latter type, the withdrawal of any single voter makes the coalition lose; whereas in the former, there can also be non-critical voters, so the coalition might be in surplus. 


\subsection{The Banzhaf index}

The absolute Banzhaf value, $f_{i}^{A B}$, has been proposed by Dubey and Shapley (1979) to catch the sum of voter $i$ s swings divided by the number $2^{n-1}$. The latter represents the overall number of coalitions, that may be winning or losing, that voter $i$ is in. The index is defined as follows:

$$
f_{i}^{A B}=\frac{\sum_{S \subseteq N}[v(S)-v(S-i)]}{2^{n-1}}
$$

The inconvenient of the absolute Banzhaf index is that it gives an absolute value of power which can not be compared to the voting shares. The normalized Banzhaf (1965) index calculates the share of a critical voter in the overall number of negative swings. Hence, it measures how important a given voter is among a group of critical voters that can all bring down a winning coalition. The normalized Banzhaf index allows thus to conclude whether a voter has more voting power than voting share in the voting body. The normalised Banzhaf index of a voter $i, f_{i}^{N B}$, is then defined as the ratio of its number of negative swings over the total number of negative swings of all voters. Formally the index is given by the following equation:

$$
f_{i}^{N B}=\frac{\sum_{S \subseteq N}[v(S)-v(S-i)]}{\sum_{j \subseteq N} \sum_{S \subseteq N}[v(S)-v(S-j)]}
$$

\subsection{Distribution of powers and stability of coalitions in the Banzhaf index}

There are indices developed in the literature that, at least indirectly, try to take account of the stability of coalitions. There are three main proposals in the literature that we present briefly to put our work in context: ${ }^{2}$

1. Johnston (1978) refines the Banzhaf calculation method to yield power indices for critical voters by taking account the overall number of critical voters. Specifically, he aims at capturing the fact that in a coalition with only one critical voter, this voter is more powerful than in a coalition where there are two critical voters, because the threat of the second to withdraw reduces the power of the first. Johnston's proposal is to divide the power index by the number of critical voters in a given coalition and to allocate the 'criticality' equally among them. Formally, his index can be written as follows, where $p$ represents the number of critical voters:

\footnotetext{
${ }^{2}$ For a more complete survey of the related literature see Pajala et alii (2002).
} 


$$
f_{i}^{J}=\frac{\sum_{S \in N} 1 / p[v(S)-v(S-i)]}{\sum_{j \subseteq N} \sum_{S \subseteq N} 1 / p[v(S)-v(S-j)]}
$$

The index therefore derives the voting power of any voter $i$ as the relative weight of this voter among critical voters, relative to the corresponding weight of other critical voters.

2. The Deegan-Packel index (1978) captures another element associated to the costs of maintaining a coalition. The authors try to capture the fact that the larger a coalition is in terms of the number of members $(q)$, the more vulnerable it is because it is generally more subject to the withdrawal of members. Hence, based on the Riker's (1962) principle of size, their index foresees that each voter of the minimum size winning coalition gets a part of the power inversely proportioned to the number of voters. The Deegan-Packel index can be written as follows:

$$
f_{i}^{D P}=\frac{\sum_{S \subseteq M} 1 / q[v(S)-v(S-i)]}{\sum_{j \in N} \sum_{S \subseteq M} 1 / q[v(S)-v(S-j)]}
$$

3. Finally, the index developed by Colomer-Martinez (1995) captures the fact that coalitions are more stable with small critical voters than with larger ones, for any given number of voters. To illustrate, consider a situation where in a parliament a large party is searching for a partner to build a coalition. Ceteris paribus, it will select among the candidates the smallest one possible to bring it just above the majority threshold. If it can avoid it, it will certainly not choose another large partner, since this may raise the political costs to keep that partner in the coalition. The importance of this consideration is underscored by the fact that in national parliaments a coalition of a large and a small partner is particularly frequent. Thus, the Colomer-Martinez index can be written as:

$$
f_{i}^{C M}=\frac{\sum_{S \in M} \frac{w_{i}[v(S)-v(S-i)]}{\sum_{j \in M} w_{j}[v(S)-v(S-j)]}}{\sum_{S \in M} v(S)}
$$

where $w$ takes account of the individual weight of the partners in the coalition.

\subsection{Capturing linkages in coalition building and departing from the critical voters}

The second line of criticism to the classical indices has tried to overcome the hypothesis of symmetric voters. This has been done by introducing linkages, preferences or ideologies of voters, in the building of coalitions. As a result, a strand of literature has engaged in developing so-called preference-based indices. Researches start by laying out a priori the political space that either pre-connects certain voters in a deterministic fashion or assigns ex ante probabilities to 
different coalitions. This then helps to exclude certain combinations or to the contrary makes 'outlier coalitions' more likely. In this strand of research, the approaches of Owen (1977 and 1982), Myerson (1977) and Bilbao (2000) consist of taking into account pre-existing coalitions' structures between similar voters. Shenoy (1981) follows this line of research introducing ideology in a Banzhaf index using geometry to define political space of voters. Perlinger (2000) extends Edelman's (1997) model and put different weights on the allowable coalitions. The underlying idea is that the possibility of coalition building is given by aligning coalition on an ideological spectrum. Along the same lines, Calvo and Lasaga (1997) and Calvo, Lasaga and van den Nouweland (1999) use probabilistic graphs to define the probability of coalition building between voters. Aleskerov (2006) defines preferences to go together in a coalition as a linear order and thus is able to rank preferred coalitions. He also describes preferences as an intensity function by extending the former voting power to cardinal information about the preferences of agents.

Furthermore, some researchers (König and Bräuninger, 1998; Bräuninger and König, 2000), developed new approaches to better describe the influence of the voting structure on voting powers such as multi-chamber voting systems. More generally, Cutrone and McCarty (2007) reviewed and analyzed the argument of bicameralism. These studies use generally spatial models since these tools have proven their usefulness through the work of Ferejohn and Shipan (1990) and Tsebelis and Money (1997). The main assumption is that the institutions themselves, through the structures of their voting bodies, may determine the extent to which players are able to influence the outcome (Steunenberg et al., 1999). Overall, these studies have been developed to study institutional structures and changes, such as bi-chambers system in legislation rather than studying voters' powers but they are useful in understanding numerical proximity as in a given game, voters are more or less able to build coalition according to the distribution of votes, the number of voters and the majority threshold.

Generally, researchers have tried to improve the Banzhaf index by refining the distribution of power among coalition participants and to introduce ideology or preference in coalition building. However, none of them deal with the fact that some voters may appear together in coalitions more often than others, given the structure of the game. In other words, these indices do not inform us about the numerical proximity between voters which may be a strong determinant of coalition building. Focusing thus on the numerical proximity permits to allocate the power over all coalition participants, rather than focusing on the pivotal voters, since a voter that permits to another one to be pivotal more often should be rewarded for that. Finally, once 
voters' numerical proximity is established, one may also consider that voters' linkages play as a kind of external proximity in the sense that voters may build coalitions together with voters with which they have stronger linkages. We develop this approach more formally in the following section.

\section{An index of proximity}

Our approach aims at providing an index that captures the frequency voters may be able to form coalitions according to the characteristics of the game. Usual voting power indices are capturing individual measures of power, i.e. by weighting the times a voter is critical or making behavioural assumptions on the probability of coalition formation. Consequently, they provide no information on the frequency voters are able to coalesce given the structure of the vote, i.e. their voting shares, the size of the voting body and the majority threshold. Therefore, this paper proposes a new measure of voting power: The numerical proximity that captures how often individual voters appear in a winning coalition together. Proximity may be defined as the bilateral frequency of coalition formation between players. It may also be defined as a normalized index to be comparable to voting shares.

Formally, our index is constructed in the following way:

1. From the allocation of votes and taken into account the number of voters and the majority threshold, the index identifies winning coalition and, as in the Banzhaf index, focuses on coalition with at least one critical voter.

2. Once critical voters are isolated, the index identifies voters sharing minimum size winning coalitions with them. The matrix $\Phi_{i j}^{X}$ is definite as $\Phi_{i j}$ which is the number of coalitions in which $j$ appears when $i$ is critical and $\Phi^{X}$ stands for type of index to be computed: $B$ stands for Banzhaf, $W$ for a weighted measure and $L$ when weights are allocated through linkages.

The proximity index in a Banzhaf set-up is therefore defined as:

$$
\Phi_{i j}^{B}:=\left\{\begin{array}{l}
\sum_{S_{\ni j}}[v(S)-v(S-i)] \quad \text { if } i \neq j, \\
0 \text { otherwise }
\end{array}\right.
$$

The definition of the weighted index is defined as:

$$
\Phi_{i j}^{W}:=\left\{\begin{array}{l}
\sum_{S \ni j} \omega_{j S}[v(S)-v(S-i)] \text { if } i \neq j, \\
0 \text { otherwise }
\end{array}\right.
$$


where $\omega_{j S}=\frac{1}{\sum_{k \in S-j} \omega_{k}}, \forall j \in S, \forall i \in S-j$, is the relative size of the particular coalition $S$.

The definition of the linkage-based index is the following:

$$
\Phi_{i j}^{L}:=\left\{\begin{array}{l}
\sum_{S \ni j} \varphi_{i j S}[v(S)-v(S-i)] \text { if } i \neq j, \\
0 \text { otherwise }
\end{array}\right.
$$

where $\varphi_{i j S}=\frac{\varphi_{i j}}{\sum_{k \in S-j} \varphi_{k j}}, \forall j \in S, \forall i \in S-j$, is the bilateral normalized relative notion of linkages between voters.

3. Finally, the index may be normalized by critical voters. Indeed, proximity has been defined as the possibility for the player $j$ to enter coalition building with player $i$ when the latter is critical. Normalized proximity will then refer to the capacity of $i$ to hoist voters when it's critical. The normalized index is defined as follows:

$$
\Psi_{i}^{X}=\frac{\sum_{j \in N} \Phi_{i j}^{X}}{\sum_{k \in N} \sum_{j \in N} \Phi_{k j}^{X}}
$$

The proximity index provides an indication of proximity between voters defined as the frequency they may build a winning coalition together, when one of them is critical. This permits to distribute power among all coalition participants uniformly or according to the size of the coalition. Introducing linkages on top proximity allows treating voters as asymmetric, eliminating thus usual critics against classical voting power indices. Table 1 below resumes the similarities and differences of the measure of proximity with the other indices introduced in the paper.

\begin{tabular}{|c|c|c|c|}
\hline Index & Admissible coalitions & Weight of voter $i$ in $S$ & Measure of power \\
\hline Banzhaf & Winning & 1 & Individual (normalized) \\
\hline Johnston & Winning & $1 / \mathrm{p}:$ number of critical voters in $S$ & Individual (normalized) \\
\hline Deegan-Packel & Minimal winning & 1/q: number of voters in $S$ & Individual (normalized) \\
\hline Colomer-Martinez & Minimal winning & w $i$ : individual weights of voters in $S$ & Individual (normalized) \\
\hline $\begin{array}{l}\text { Proximity à la Banzhaf } \\
\text { Weighted Proximity à } \\
\text { la Deegan-Packel } \\
\text { Linkage-based } \\
\text { Proximity }\end{array}$ & Minimal winning & $\begin{array}{l}\text { 1/q: number of voters in } S \\
\varphi i j: \text { bilateral normalized notion of } \\
\text { linkages between voter } j \text { and } i \text { in } S\end{array}$ & $\begin{array}{l}\text { Bilateral between voter } i \\
\text { and } j \text { and individual } \\
\text { (normalized to voter } i \text { ) }\end{array}$ \\
\hline
\end{tabular}

Table 1: Description of voting power indices and the proximity measure of voting power 


\section{Applications to the IMF EB}

\subsection{Applications of the Banzhaf index to the IMF}

Our applications focuses on decisions requiring a simple majority, i.e. over $50 \%$ of total votes and consider mainly the voting power within the 24 member-body. ${ }^{3}$ Table 2 below reports the Banzhaf index in such a way to make our results comparable to the few studies dealing with voting power in the IMF Executive Board, namely Leech (2002), Leech and Leech (2005), Alonso-Meijide and Bowles (2005) and Bini Smaghi (2006). Voting shares (column A) and Banzhaf index (column B) are reported. Their results indicate that the voting structure of the IMF EB gives disproportionate power to the United States at the expense of all other members. This means that for the United States, effective voting power exceeds their notional voting share, whereas for all other 23 constituencies the opposite result holds. Alonso-Meijide and Bowles (2005) generated functions for the Banzhaf index. Instead of considering a game over the whole set of players, they defined it over some subsets of the set of players and apply it to the IMF. Their results (column C) are able to account for both within and between unions' allocation of rewards and put forward the fact that the US may be more powerful than the classical Banzahf index predicts. However, the authors acknowledge that their index can not overcome the fact that all possible coalitions (restricted by a priori unions) are not equally likely and 'may depend, like the constituencies' composition, on regional, historical and geostrategic aspects" (Alonso-Meijide and Bowles, 2005).

Table 2: Voting shares, Banzhaf index and a priori Banzhaf index: Results of previous studies

\begin{tabular}{|c|c|c|c|}
\hline $\begin{array}{r}\text { Executive } \\
\text { directors }\end{array}$ & Voting share & Banzhaf index & $\begin{array}{c}\text { A priori Banzhaf } \\
\text { index }\end{array}$ \\
\hline United States & 17.1 & 21.6 & 24.7 \\
\hline Japan & 6.1 & 5.9 & 5.5 \\
\hline Germany & 6.0 & 5.7 & 5.4 \\
\hline Belgium & 5.1 & 5.2 & 4.9 \\
\hline France & 5.0 & 4.7 & 4.5 \\
\hline United Kingdom & 5.0 & 4.7 & 4.5 \\
\hline Netherlands & 4.9 & 4.6 & 4.5 \\
\hline Mexico & 4.3 & 4.1 & 3.9 \\
\hline Italy & 4.2 & 4.0 & 3.8 \\
\hline Canada & 3.7 & 3.6 & 3.4 \\
\hline Norway & 3.5 & 3.3 & 3.2 \\
\hline Korea & 3.3 & 3.2 & 3.1 \\
\hline Egypt & 3.2 & 3.1 & 3.0 \\
\hline Saudi Arabia & 3.2 & 3.0 & 2.9 \\
\hline Malay sia & 3.1 & 3.0 & 2.9 \\
\hline Tanzania & 2.9 & 2.8 & 2.7 \\
\hline China & 2.9 & 2.8 & 2.7 \\
\hline Switzerland & 2.7 & 2.6 & 2.5 \\
\hline Russia & 2.6 & 2.5 & 2.4 \\
\hline Iran & 2.5 & 2.3 & 2.3 \\
\hline Brazil & 2.4 & 2.3 & 2.2 \\
\hline India & 2.4 & 2.3 & 2.2 \\
\hline Argentina & 2.0 & 1.9 & 1.9 \\
\hline Equatorial Guinea & 1.2 & 1.1 & 1.1 \\
\hline
\end{tabular}

\footnotetext{
${ }^{3}$ The Annex A presents the governance structure of the IMF and describes more precisely the voting structure.
} 
Furthermore, one might look at voting power inside constituencies applying Banzahf index within constituencies. Eight directors represent a single country - the United States, Japan, Germany, France, United Kingdom, China, Saudi-Arabia and Russia (ranked by descending quota). The remaining 16 directors represent constituencies, which comprise between 4 and 24 countries. One can also use the Banzhaf index to shed light on the current situation regarding voting power and Executive directors' nomination within individual constituencies. Selected for illustrative purposes, Table 3 shows voting shares and Banzhaf indices for the three constituencies currently led by Italy, Belgium and Venezuela. Assessing the constituency led by Italy is straightforward, as Italy's voting share in the constituency equals $77.8 \%$ and thus translates into a voting power of $100 \%$. Therefore, this country's historical position as a leader appears very clearly. However, the picture is different for the Belgian constituency, where Belgium's share at $41.45 \%$ is large but below the majority threshold. Belgium's Banzhaf index shows that its effective power is $64.8 \%$, far ahead of those of other members, but still illustrating the needs to engage other partners in a coalition. As for constituency currently led by Venzuela, voting power analysis can explain why leadership rotates between the three largest countries, Spain, Mexico and Venezuela, rather than being led always by Mexico as the country with the highest quota. The reason is that in this specific constellation despite different shares, voting power equals exactly $33 \%$ for all three largest countries and is strictly zero for the other five members.

Table 3: Voting shares and Banzhaf index within constituencies

\begin{tabular}{|c|c|c|}
\hline $\begin{array}{r}\text { Executive } \\
\text { directors }\end{array}$ & Voting share & Banzhaf index \\
\hline Albania & 0.0081 & 0.0000 \\
\hline Greece & 0.0932 & 0.0000 \\
\hline Italy & 0.7784 & 1.0000 \\
\hline Malta & 0.0140 & 0.0000 \\
\hline Portugal & 0.0981 & 0.0000 \\
\hline San Marino & 0.0046 & 0.0000 \\
\hline Timor-Leste & 0.0036 & 0.0000 \\
\hline Costa Rica & 0.0192 & 0.0000 \\
\hline El Salvador & 0.0199 & 0.0000 \\
\hline Guatemala & 0.0238 & 0.0000 \\
\hline Honduras & 0.0157 & 0.0000 \\
\hline Mexico & 0.3221 & 0.3333 \\
\hline Nicaragua & 0.0157 & 0.0000 \\
\hline Spain & 0.3116 & 0.3333 \\
\hline Venezuela & 0.2721 & 0.3333 \\
\hline Austria & 0.1665 & 0.0670 \\
\hline Belarus & 0.0361 & 0.0223 \\
\hline Belgium & 0.4063 & 0.6480 \\
\hline Czech Republic & 0.0741 & 0.0615 \\
\hline Hungary & 0.0933 & 0.0615 \\
\hline Kazakhstan & 0.0343 & 0.0223 \\
\hline Luxembourg & 0.0267 & 0.0223 \\
\hline Slovak Republic & 0.0336 & 0.0223 \\
\hline Slovenia & 0.0225 & 0.0056 \\
\hline Turkey & 0.1067 & 0.0670 \\
\hline
\end{tabular}




\subsection{Applications of the proximity index}

As a first step, we compute our new index in bilateral terms within a Banzhaf framework (index $\Phi_{i j}^{B}$ illustrated in Chart 1.a), as well as the weighted measure of proximity (index $\Phi_{i j}^{W}$ illustrated in Chart 1.b). This bilateral illustration is not normalized and proposed in chart 1 below. The domination of the US in the Executive Board is illustrated by its presence in most of the winning coalition as shown on the top left panel of chart 1.a. This domination may also be seen in the right panel of chart 1.b since the United States permits to its allies to increase their chance to be in a winning coalition. Indeed, when the US is critical, since it is the largest voter, it permits to the other players to ensure relatively more acceptance. In other words, it is more rewarding to build a coalition with the US than with smaller voters since building a coalition with US increase the probability to become a critical voter. Moreover, since the US is a large player, it is present in a large number of winning coalitions and is therefore also greatly rewarded. Finally, we computed our new index in bilateral terms accounting for linkages between members (index $\Phi_{i j}^{L}$ illustrated in Chart 1.c). The US is still dominant since they appear in a large number of coalitions. Interestingly, some constituencies are emerging: Canada, Venezuela and Brazil. Our linkage-based measure of proximity permits to identify the fact that these constituencies are more likely to enter coalition building with the US than others. Not surprisingly, since the US are the most important members in the IMF, the linkage-based index captures the fact that countries that are closely related to the US, i.e. that trade much with them, gain from the fact that the US is the largest member in the voting body. Indeed, since Canada and Venezuela trade much with the US, both have a stronger will to share a coalition with the US and the inverse is true since the US trade much with these countries. Another interesting case is the one of the UK and France. Indeed, these two countries have exactly the same voting share of $4.86 \%$ in the IMF inducing that they have the same Banzhaf value. Still, the historical political position of the UK is oriented towards a quasi-unconditional support to the US. The results of the linkage-based index explain UK's strategy since their power is larger than the one of France, respectively $4.0 \%$ and $3.65 \%$ in normalized terms as shown in table 4 below. The same applies also for Iran and Brazil. Indeed, both have the same voting share of $2.42 \%$ and the same Banzhaf value of $2.3 \%$. However, Brazil is much closer to the US than Iran. As a result, the voting power of Brazil is $2.67 \%$ whereas Iran gets $1.96 \%$. 

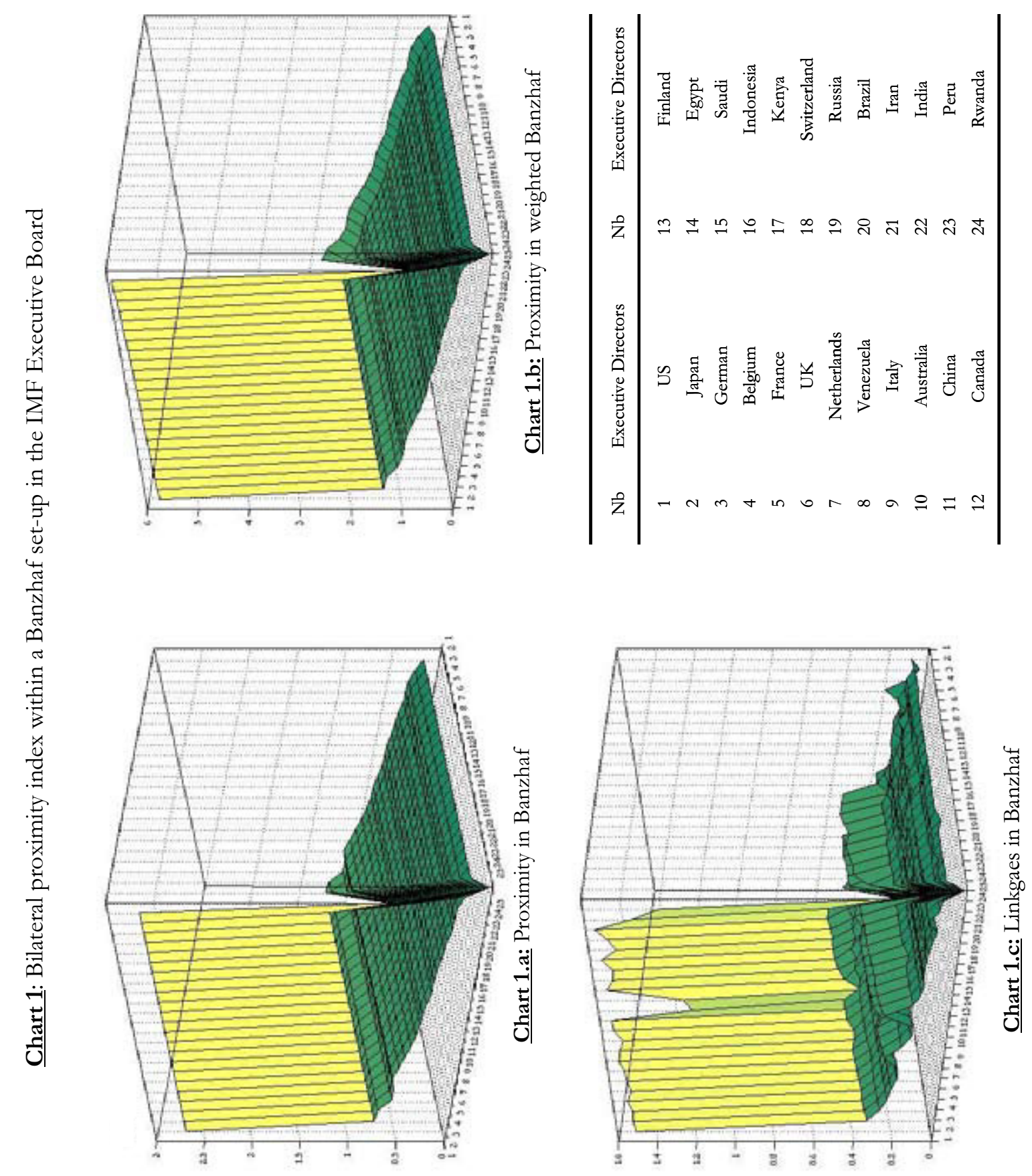
Table 4: Voting shares, Banzhaf and proximity normalized indices in the IMF Executive Board

\begin{tabular}{rcccc}
\hline Executive directors & Voting share & $\begin{array}{c}\text { Normalized Banzhaf Normalized Weighted } \\
\text { index }\end{array}$ & $\begin{array}{c}\text { Normalized Linkage- } \\
\text { Proximity index }\end{array}$ & $\begin{array}{c}\text { based Proximity } \\
\text { index }\end{array}$ \\
\hline United States & 16.80 & 20.93 & 23.43 & 25.56 \\
Japan & 6.02 & 5.74 & 5.68 & 5.86 \\
German & 5.88 & 5.61 & 5.54 & 4.79 \\
Belgium & 5.15 & 4.91 & 4.81 & 4.23 \\
France & 4.86 & 4.63 & 4.52 & 3.65 \\
United Kingdom & 4.86 & 4.63 & 4.52 & 4.00 \\
Netherlands & 4.76 & 4.53 & 4.42 & 3.75 \\
Venezuela & 4.45 & 4.23 & 4.12 & 5.24 \\
Italy & 4.11 & 3.91 & 3.79 & 3.58 \\
Australia & 3.85 & 3.66 & 3.54 & 2.96 \\
China & 3.66 & 3.48 & 3.36 & 2.97 \\
Canada & 3.64 & 3.46 & 3.34 & 3.87 \\
Finland & 3.44 & 3.27 & 3.15 & 2.11 \\
Egypt & 3.20 & 3.04 & 2.92 & 2.42 \\
Saudi Arabia & 3.17 & 3.01 & 2.89 & 2.58 \\
Indonesia & 3.12 & 2.96 & 2.84 & 2.50 \\
Kenya & 2.94 & 2.79 & 2.67 & 2.38 \\
Switzerland & 2.79 & 2.65 & 2.53 & 2.16 \\
Russia & 2.70 & 2.56 & 2.45 & 2.67 \\
Brazil & 2.42 & 2.30 & 2.19 & 1.96 \\
Iran & 2.42 & 2.30 & 2.19 & 1.93 \\
India & 2.35 & 2.23 & 2.12 & 1.83 \\
Peru & 1.96 & 1.86 & 1.76 & \\
Rwanda & 1.39 & 1.32 & 1.24 &
\end{tabular}

Another illustration of the innovation of the proximity index can be seen when dealing with voting inside constituencies. We employ the same examples as above, focusing on the Belgium constituency. Chart 2 and Table 5 below expose the results of the bilateral and normalized indices. Within the Belgian constituency, Banzhaf index predicts the same power of $6.7 \%$ for Austria and Turkey while their voting shares are $16.65 \%$ and $10.67 \%$, respectively. In this situation, classical indices do not account for the stability of the coalitions, since some members with very different weights gets the same power. In other words, classical indices' view is biased because they do not discount the distribution of power for the relative size of coalitions. Weighting the index permits to estimate coalition building in a stability perspective since smaller voters should get less power. Indeed, in our example, if Belgium enters a coalition with any of these two countries, the coalition will be a strictly minimum size winning one. Banzhaf predicts therefore the same distribution of power between them. However, the weighted proximity index is able to capture the fact that Austria is larger than Turkey and should thus be more rewarded since Austria should be in principle in a larger number of winning coalitions. The results confirm this since the values of Austria and Turkey are respectively 5.48\% and $4.92 \%$. Finally, introducing linkages between voters permits to explain that Belgium has historically been the Executive Director of this constituency. 

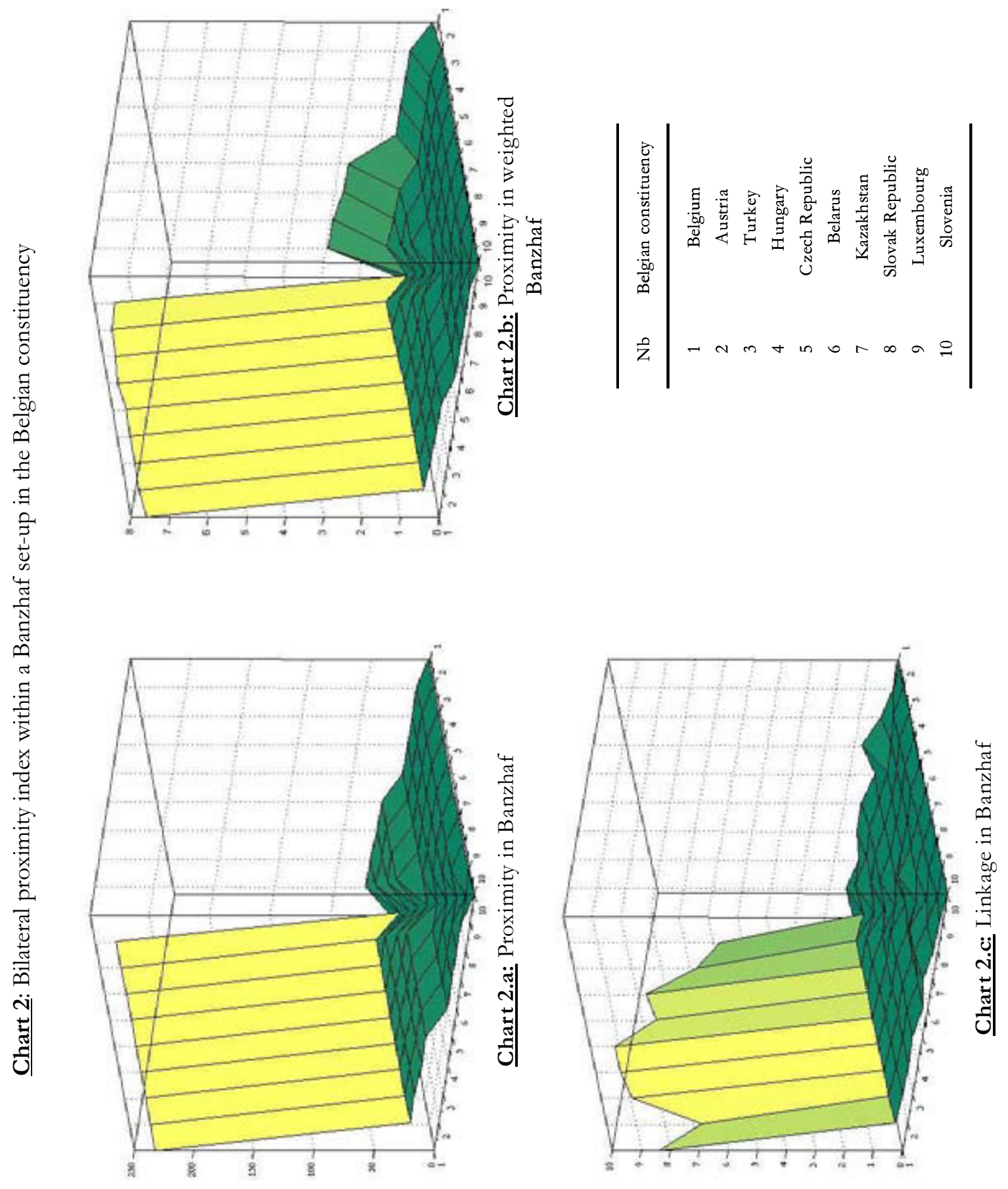
Table 5: Voting shares, Banzhaf and proximity normalized indices in the Belgian constituency

\begin{tabular}{rcccc}
\hline Belgian constituency & Voting share & $\begin{array}{c}\text { Normalized Banzhaf } \\
\text { index }\end{array}$ & $\begin{array}{c}\text { Normalized } \\
\text { Weighted Proximity } \\
\text { index }\end{array}$ & $\begin{array}{c}\text { Normalized Linkage- } \\
\text { based Proximity } \\
\text { index }\end{array}$ \\
\hline Austria & 0.1665 & 0.0670 & 0.0548 & 0.0455 \\
Belarus & 0.0361 & 0.0223 & 0.0150 & 0.0163 \\
Belgium & 0.4063 & 0.6480 & 0.7455 & 0.7684 \\
Czech Republic & 0.0741 & 0.0615 & 0.0429 & 0.0353 \\
Hungary & 0.0933 & 0.0615 & 0.0442 & 0.0312 \\
Kazakhstan & 0.0343 & 0.0223 & 0.0150 & 0.0316 \\
Luxembourg & 0.0267 & 0.0223 & 0.0148 & 0.0148 \\
Slovak Republic & 0.0336 & 0.0223 & 0.0150 & 0.0161 \\
Slovenia & 0.0225 & 0.0056 & 0.0037 & 0.0028 \\
Turkey & 0.1067 & 0.0670 & 0.0492 & 0.0379 \\
\hline Source: IMF; 2007; autbors' computations & & &
\end{tabular}

Finally, we propose a simulation exercise. It may be informative to measure for example the impact of a change in the structure of the IMF executive Board. Leech and Leech (2005) computed Banzhaf index for different possible European single seats. They found that such a configuration may counterbalance the actual power of the United States and enhance the power of non-EU members and EU members. Bini Smaghi (2006) runs such a simulation adding a G7 predefined coalition and found similar results. In this paper, we regroup only the three Member States that have their own seat: Germany, France and the UK, to avoid the problem of countries' reallocation between constituencies. These countries have been chosen for illustrative purposes of the technical index only, and this is not necessarily judged to be a realistic scenario. Their aggregate voting share of $16.8 \%$ is indeed balancing the current position of the US. This is translated in a Banzhaf index of $17.8 \%$ for the US and $15.8 \%$ for the single EU seat (see table 6). The US is not losing its dominant position but their power is reduced somewhat. If we now look at the result of our numerical proximity index, the $\Phi_{i j}^{W}$, not surprisingly, both the US and the EU single seat found to gain in relatively more in voting power. Still, the US is gaining more than the EU single seat. Interestingly, when computing our $\Phi_{i j}^{L}$ index, the dominant position of the US is still not thwarted by the important number of Europeans around the table of the Executive Board. Interestingly, differences emerge when looking at chart 3.c. Indeed, while Japan and the US are more likely to build coalition together, it is not the case of the EU. However, the EU seat would rather build a coalition with the Belgian, the Dutch and the Italian constituencies, reflecting thus the relative importance of linkages between voters. 

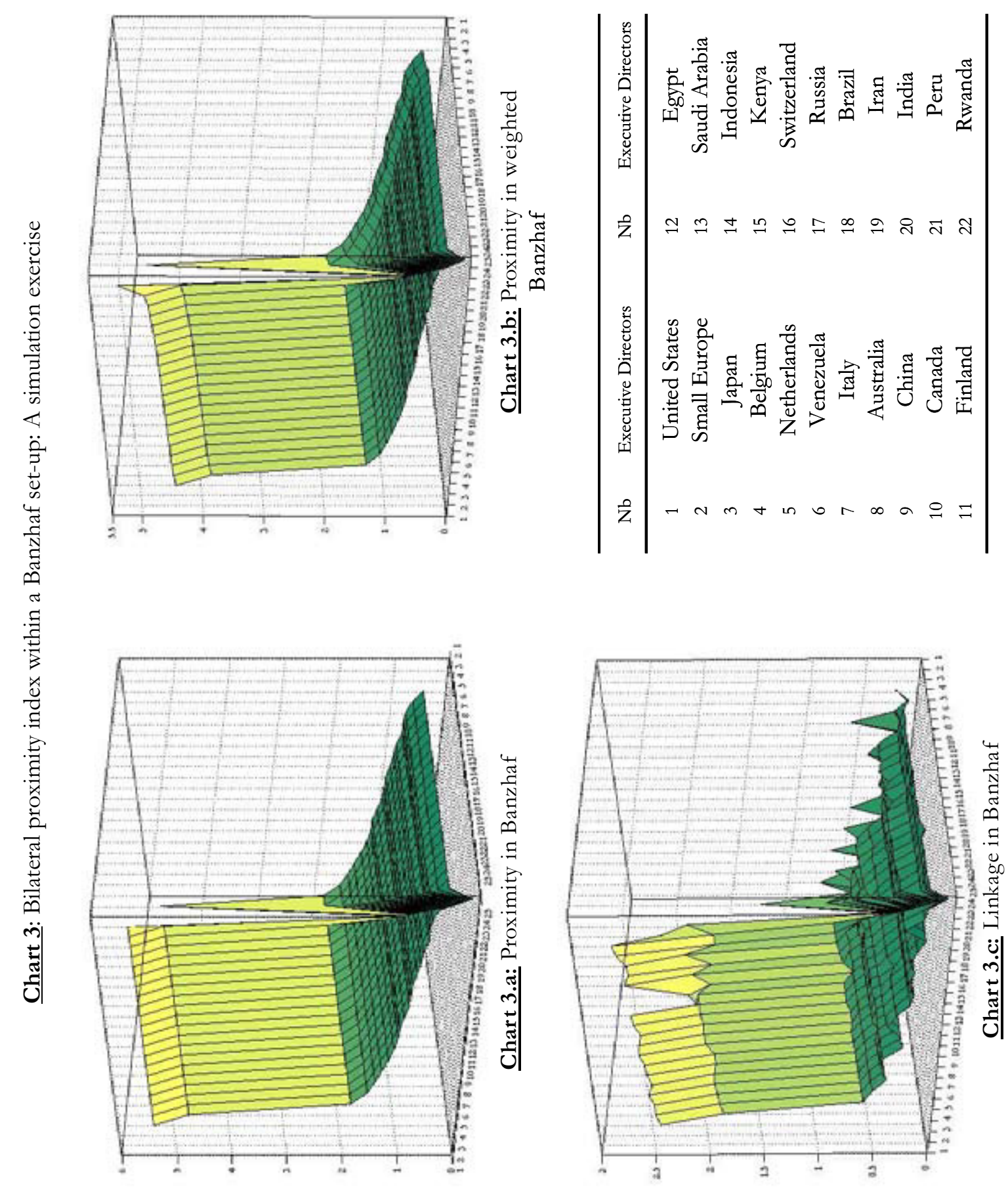
Table 6: Voting shares, Banzhaf and proximity normalized indices: A simulation exercise

\begin{tabular}{rcccc}
\hline Executive directors & Voting share & $\begin{array}{c}\text { Normalized Banzhaf } \\
\text { index }\end{array}$ & $\begin{array}{c}\text { Normalized } \\
\text { Proximity index }\end{array}$ & $\begin{array}{c}\text { Normalized Linkage- } \\
\text { based Proximity index }\end{array}$ \\
\hline United States & 16.80 & 17.81 & 19.72 & 22.83 \\
DE-U K-FR & 15.61 & 15.76 & 17.20 & 17.59 \\
Japan & 6.02 & 6.03 & 5.86 & 5.47 \\
Belgium & 5.15 & 5.11 & 4.92 & 4.77 \\
Netherlands & 4.76 & 4.70 & 4.52 & 4.28 \\
Venezuela & 4.45 & 4.39 & 4.20 & 4.18 \\
Italy & 4.11 & 4.05 & 3.86 & 2.58 \\
Australia & 3.85 & 3.78 & 3.60 & 2.80 \\
China & 3.66 & 3.59 & 3.41 & 4.17 \\
Canada & 3.64 & 3.57 & 3.39 & 3.38 \\
Finland & 3.44 & 3.37 & 3.19 & 2.30 \\
Egypt & 3.20 & 3.13 & 2.96 & 2.12 \\
Saudi Arabia & 3.17 & 3.11 & 2.93 & 2.24 \\
Indonesia & 3.12 & 3.06 & 2.88 & 2.75 \\
Kenya & 2.94 & 2.88 & 2.71 & 2.19 \\
Switzerland & 2.79 & 2.73 & 2.56 & 3.44 \\
Russia & 2.70 & 2.64 & 2.48 & 1.56 \\
Brazil & 2.42 & 2.36 & 2.21 & 1.85 \\
Iran & 2.42 & 2.36 & 2.21 & 1.65 \\
India & 2.35 & 2.30 & 2.15 & 1.52 \\
Peru & 1.96 & 1.91 & 1.78 & \\
Rwanda & 1.39 & 1.36 & 1.26 &
\end{tabular}

\section{Conclusions}

In this paper, we have presented a new framework to capture the numerical proximity of voters in coalition building. While standard voting power indices, such as the Banzhaf index, capture the relative importance of critical voters, our index gives a bilateral representation of power as the frequency voters may build coalition together according to the voting body's structure and to the linkages among coalition participants. We first introduce the notion of proximity in a Banzhaf framework. Second, we proposed to weight the distribution of power $a$ la Deegan-Packel by the relative size of the coalitions. Third, we included linkages among participants as a determinant of coalition building.

We are particularly interested in understanding decision making at the International Monetary Fund and hence apply our index to the countries and constituencies represented at the Fund's Executive Board. We computed our new measure in two steps allowing capturing first the numerical proximity of voters and second the linkages between voters within the Executive Board of the IMF. For this application in the context of international economic cooperation, we use bilateral trade as an indicator reflecting the importance of countries' relationships. The results are able to explain several important features of IMF Executive Board functioning, and more broadly of international politics.

Looking ahead, more work is needed on the definition of the proximity measure, its properties and its application within other voting power indices. On the practical side, to better measure and conceptualize linkages among coalition participants remains a challenging but appealing issues for further research. 


\section{Bibliography}

ALESKEROV, F, 2006. Power Indices Taking Into Account Agent's Preferences. In Mathematical and Democracy, Recent Advances in Voting Systems and Collective Choice. Simeon \& Pukelshein (Eds.), Springer.

ALONSO-MEIJIDE, J.M., BOWLES, C., 2005. Generating Functions for Coalitional Power Indices: An Application to the IMF. Annals of Operations Research 137, pp. 21-44.

ANDERSON, J., MARCOUILLER, D., 2002. Insecurity and the Pattern of Trade: An Empirical Investigation, Review of Economics and Statistics, Vol. 84:2.

ANDERSON, J., VAN WINCOOP, E., 2004. Trade Costs, Journal of Economic Literature Vol. XLII.

BALDWIN, BERGLOF, E., GIAVAZZI, F., WIDGREN, M., 2000. EU Reforms for Tomorrow's Europe. CEPR Discussion Paper Series, No. 2623.

BANZHAF J., 1965. Weigthed Voting Doesn't Work : A Mathematical Analysis, Rutgers Law Review 19, p. 317-343.

BILBAO J.M., Cooperative Games on Combinatorial Structures, Kluwer Publisher, 2000.

BINI SMAGHI, L., 2006. IMF Governance and the Political Economy of a Consolidated European Seat, in Reforming the IMF for the $21^{\text {st }}$ century, E. Truman Ed., Institute for International Economics.

BRÄUNINGER, T., KÖNIG, T., 2000. Making Rules for Governing Global Commons. The Case of Deep-sea Mining, Journal of Conflict Resolution 44(5): 604-29.

CALVO, E., LASAGA, J, 1997. Probabilistic Graphs and Power Indices: An Application to the Spanish Parliament, Journal of Theoretical Politics, Vol. 9.

CALVO, E., LASAGA, J., VAN DEN NOUWELAND, A., 1999. Values of Games With Probabilistic Graphs. Mathematical Social Sciences, Vol. 37.

CHEN, N., 2002. Intra-national versus International Trade in the EU: Why Do National Borders Matter? CEPR Discussion Paper Series, No. 3402.

COLOMER J.M., F. MARTINEZ, 1995. The Paradox of Coalition Trading, Journal of Theoretical Politics 7, p. 41-63.

CUTRONE, M., McCARTY, N., 2007. Do Bicameralism Matter?, mimeo.

DEEGAN J., E.W. PACKEL, 1978. A New Index of Power for Simple n-Person Games, International Journal of Game Theory 7, p. 113-123.

DUBEY, P., SHAPLEY, L., 1979. Mathematical Properties of the Banzhaf Power Index, Mathematics of Operations Research 4(2), pp. 99-131.

EATON, J., KORTUM, S., 2002. Technology, Geography and Trade, Econometrica Vol. 70:5.

EDELMAN, P., 1997. A Note on Voting. Mathematical Social Science, Vol. 34.

ESTEVADEORDAL, A, FRANTZ, B., TAYLOR, A., 2003. The Rise and Fall of World Trade, 1870-1939, Quarterly Journal of Economics, Vol. 68:2.

EVANS, C., 2001. The Cost of Outsourcing, Working Paper Board of Governors of the Federal Reserve System.

FEREJOHN, J., SHIPAN, C., 1990. Congressional Influence on the Bureaucracy, Journal of Law, Economics, and Organization 6(SI):1-20. 
GUPTA, D., 2003. Coalitions in Theory and Practice: A Critical Review of Existing Research. Seminar on Modern European Politics, Cornell University, the 30 April 2003.

HAARIGAN, J., 1993. OECD Imports and Trade Barriers in 1983, Journal of International Economics, Vol. 34:1.

HEAD, K., RIES, J., 1998. Immigration and Trade Creation: Evidence from Canada, Canadian Journal of Economics, Vol. 31:1.

HEAD, K., MAYER, T., 2000. Non-Europe: The Magnitude and Causes of Market Fragmentation in the UE, Weltwirtschaftliches Archives, Vol. 136:2.

HUMMELS, D., 2001. Toward a Geography of Trade Costs, Working Paper, Purdue University.

JOHNSTON R., 1978. On the Measurement of power : Some Reactions to Laver, Environment and Planning 10, p. 907-914.

KIRMAN, A., WIDGREN, M., 1995. European Economic Decision-Making Policy: Progress or Paralysis? Economic Policy, vol. 10, No. 21.

KÖNIG, T., BRÄUNINGER, T., 1998. The Inclusiveness of European Decision Rules, Journal of Theoretical Politics 10(1): 125-41.

KRUGMAN, P., 1991. Geography and trade, MIT Press, Cambridge MA.

LARUELLE, A., WIDGREN, M., 1998. Is the allocation of voting power among EU states fair?. Public Choice, Vol. 94, 317-339.

LEECH, D., 2001. Designing the voting system for the Council of the European Union. Public Choice, Vol. 112, 437-464.

LEECH, D., 2002. Voting power in the governance of the International Monetary Fund. Annals of Operations Research, Vol. 109, 375-397.

LEECH, D., LEECH, R., 2005. Voting power in the Bretton Woods Institutions. Homo Oeconomicus, 22(4):1-23.

LOPEZ-CORDOVA, E., MEISSNER, J., 2003. Exchange Rate Regimes and International Trade: Evidence from the Classical Gold Standard Era, American Economic Review, Vol. 93:1.

MARTIN, P., MAYER, T., THOENIG, M.., 2006. Make Trade Not War. CEPR Discussion Paper Series No. 5218.

MONTESQUIEU, C. L., 1758. De l'esprit des Lois, Folio 1995 Ed.

MYERSON R., 1977. Graphs and Cooperation in Games, Mathematics of Operations Research 2, p. 225-229.

OWEN G., 1977. Values of Games with a priori Unions, in R. Hein and O. Moeschlin (eds), Essays in Mathematical Economics and Game Theory, Springer Verlag.

OWEN G., 1982. Modification of the Banzhaf-Coleman Index for Games with a prior Unions, in : M. J. Holler (ed.), Power, Voting and Voting Power,Würzburg-Vienna, Physica Verlag.

PAJALA A., T. MESKANEN et T. KAUSE, Voting Power Website, http ://powerslave.val.utu.fi, 2002.

PENROSE L.S., 1946. The Elementary Statistics of Majority Voting », Journal of the Royal Statistical Society 109, p. 53-57. 
PERLINGER, T, 2000. Voting Power in an Ideological Spectrum. The Markov-Polya Index. Mathematical Social Sciences, Vol. 40.

PORTES, R., REY, H., 2005. The Determinants of Cross-Border Equity Transaction Flows, Journal of International Economics, Vol. 65.

RAUCH, J., TRINDADE, V., 2002. Ethnic Chinese Networks in International Trade, Review of Economics and Statistics, Vol. 84:1.

ROSE, A., VAN WINCOOP, E., 2001. National Money as a Barrier to Trade: The Real Case fro Currency Union, American Economic Review Papers and Proceedings, Vol. 91:2.

ROSE, A., 2004. The Effects of Common Currencies on International Trade: A Meta Analysis, in Monetary Union and Hard Pegs: Effects on Trade and Financial Development and Stability. Alexander, Melitz and Von Furstenberg Eds.

SHAPLEY L.S. et M. SHUBIK, 1954. A Method for Evaluating the Distribution of Power in a Committee System, American Political Science Review 48, p. 787-792.

SHENOY, P, 1982. The Banzhaf Power Index for Political Games. Mathematical Social Sciences, Vol. 2.

SKALA, M., THIMANN, C., WÖLFINGER, R., 2007. The search for Columbus' egg: finding a new formula to determine quotas at the IMF. ECB Occasional Paper no. 70, August.

SRIVASTAVA, R. K., GREEN, R. T., 1986. Determinants of Bilateral Trade-Flows, Journal of Business 59, 623-640.

STEUNENBERG, B., SCHMIDTCHEN, D., KOBOLDT, C., Strategic Power in the European Union: Evaluating the Distribution of Power in Policy Games

STRAFFIN P.D., 1977. Homogeneity, Independance and Power Indices, Public Choice 30, , p. 107-118.

TSEBELIS, G., MONEY, J., 1997. Bicameralism. New York: Cambridge University Press.

VON NEUMANN, J., MORGENSTERN, O, 1944. Theory of Games and Economic Behavior, Princeton University Press, Princeton, 3rd. Ed., 1953. 


\begin{abstract}
ANNEX A
Decision process at the International Monetary Fund

In the IMF, the votes of each of the 184 member countries are determined by the member's quota - a variable broadly determined by a country's relative economic position but including political judgement plus a small number of so-called basic votes that are distributed equally across members (see Skala et al., 2007, for an overview of the role of IMF quotas and the ongoing reform).$^{4}$

Originally conceived to favour smallest members, the overall share of basic votes has declined continuously from $11.3 \%$ of total votes in the 1950 s to only $2.1 \%$ of total votes today. When a country joins, it is assigned an initial quota in the same range as the quotas of existing members considered to be broadly comparable in economic size and characteristics. Quotas have a fourfold function: They determine the maximum amount of resources a member is called upon to provide to the institution, serve as the basis for voting rights, determine the distribution of Special Drawing Rights allocations and serve as the basis for access to resources. Quotas are calculated on the basis of a set of formulas. ${ }^{5}$ The main decision making body is the Executive Board, which is responsible for conducting the day-to-day business of the IMF. It is composed of 24 Directors, who are appointed or elected by member countries or by groups of countries, and it is chaired by the Fund's Managing Director. The Executive Board usually meets three times each week and carries out its work largely on the basis of papers prepared by IMF management and staff. The bulk of decisions of the Fund are taken by a simple majority of the votes cast. ${ }^{6}$ However, for a number of specific votes, thresholds of $70 \%$ and $85 \%$ are required (see Table A1 below).
\end{abstract}

\title{
Table A1: Minimum threshold for decisions at the IMF Executive Board
}

The bulk of decisions require a simple majority of votes cast.

Decision requiring a $70 \%$ majority include:

- Suspension or reinstatement of voting rights

- Determination of rates of charge or remuneration

- Valuation of SDR: Other change than fundamental change in principle

- Determination of rate of interest on SDRs

Decision requiring a $85 \%$ majority include:

- Amendment of the IMF's Articles of Agreement*

- Adjustment of quotas

- Allocation of SDRs

- Sale of gold

- Compulsory withdrawal from the IMF (exclusion of a member)

Source: IMF. *In this case, a majority of three-fifths of the members having $85 \%$ of the voting power is needed.

\footnotetext{
${ }^{4}$ There are also 250 so-called basic votes that every member receives, in addition to one vote for each SDR 100,000 in quota. For the median IMF member in terms of quota, Argentina, total votes consist of the 250 basic votes plus 30,000 votes from its quota. Hence, the basic votes are relevant only for very small countries.

5 The first formula was used in 1944 as a basis for determining the broad configuration of the initial quota distribution became known as the Bretton Woods formula. This formula contained five variables: national income, official reserves, imports, export variability, and the ratio of exports to national income. A multi-formula approach was introduced in the early 1960s, when the Bretton Woods formula was supplemented with four other formulas containing the same basic variables but with larger weights for external trade and external variability. The quota formulas were last modified in the context of the Eighth General Review (1982/83) but their basic structure was retained. For each of the four non-Bretton Woods formulas, quota calculations are multiplied by an adjustment factor so that the sum of the calculations across members equals that derived from the Bretton Woods formula.

${ }^{6}$ The actual voting process is somewhat more complicated: Whenever voting is required under Article V (Section 4 or 5), each member has the number of votes to which it is entitled adjusted by the addition of one vote for the equivalent of each SDR 400,000 of net sales of its currency from the general resources of the Fund up to the date when the vote is taken, or the subtraction of one vote for the equivalent of each four hundred thousand special drawing rights of its net purchases under Article V (Section 3(b) and (f)) up to the date when the vote is taken, provided that neither net purchases nor net sales shall be deemed at any time to exceed an amount equal to the quota of the member involved.
} 


\section{ANNEX B}

\section{Determinants of coalition building in the international financial institutions}

In the special case of international politics, for which the Bretton Woods institutions are good examples, decisions are involving in most of the case an action (financial or not) on a member or a group of members. The IMF decides on financial assistance to members, on organising principles of the international monetary system (rules of cooperation, sharing of financial contributions among members, composition of the special drawing rights, etc.) and on members' compliance with these principles (for example in the surveillance framework that can entail decisions on whether countries comply with their obligation to report data to the Fund and maintain policies that are conducive to overall international stability). Moreover, the IMF promotes international monetary cooperation more broadly including through the provision of analysis of international linkages and spillovers, it gives policy advice to members and it provides technical assistance to help countries build and maintain strong economies. The World Bank decides on loans and grants for project in member countries, and it lays the rules for international development assistance.

Therefore, coalition building is likely to be influenced a priori by economic bilateral relations between members. ${ }^{7}$ Of course, we cannot ignore the general policy content of IMF and World Bank interventions, and the choice of the proxy to account for economic bilateral relations between members should therefore capture this element. In this respect, we believe that bilateral trade between members is a reasonable first candidate as a proxy for a measure of proximity between members of the Executive board of the IMF and the World Bank. For one thing, one should choose a proxy that captures not only economic, but also political relations between countries. In this respect bilateral trade seems to be a link that goes well beyond pure exchange of goods and services, as pointed out already by Montesquieu in his essay De l'esprit des Lois (1758):

"Two nations which trade together, render themselves reciprocally dependent; for if one has an interest in buying, the other has an interest in selling; and all unions are based upon mutual needs."

Studies dealing with international trade have focused for a long time on explaining the relation between trade and conflict. Indeed, the liberal view in political science argues that increasing trade flows, enhancing free markets and democracy should limit the incentive to use military force in interstate relations. For example, Martin et al. (2006) argue that bilateral trade deters bilateral war, because it increases the opportunity cost of bilateral war. Moreover, as suggested by the geographic economic literature (see Anderson and van Wincoop, 2004 for a survey), bilateral trade is a superior proxy for bilateral relations between countries because it captures the border effect associated by at least 6 determinants: (1) the distance barrier (Srivastava and Green, 1986; and Krugman, 1991), (2) the language barrier (Eaton and Kortum, 2002; and Hummels, 2001), (3) the currency barrier (Rose and Wincoop, 2001; Rose, 2004, Estevadeordal, Frantz and Taylor, 2003; and Lopez-Cordova and Meissner, 2003), (4) the informational barrier (Portes and Rey, 2005; Rauch and Trindade, 2002; Head and Ries, 1998), (5) the contracting costs and insecurity barrier (Evans, 2001; Anderson and Marcouiller, 2002) and (6) the non-tariff policy barrier (Haarigan, 1993; Head and Mayer, 2000; and Chen, 2002). Finally, Rose (2004) has shown using a gravity model that bilateral trade may also capture historical (i.e. colonial) and geographic dimensions.

Table A2 below shows bilateral flows between countries represented at the table of the IMF Executive Board (with origin countries in columns). We are now able to define a priori policy space of members. Chart A2.1 below illustrate this for two interesting countries, the US and Germany. Indeed, as we can see, bilateral relations can be illustrated by a sort of 'snail' if we rank members by decreasing intensity of bilateral trade. We note for example that Germany's trade is spread more equally across trading partners (with France taking the highest share at about 17\%), whereas US external trade is more heavily concentrated (with Canada taking the highest share at 30\%). In political terms, we can interpret, these distributions loosely speaking as exports of country $\mathrm{X}$ to country $\mathrm{Y}$ capturing how much country $\mathrm{X}$ can influence country $\mathrm{Y}$ ' and imports of country $\mathrm{Y}$ to country $\mathrm{X}$ capturing 'how much country X can be influenced by country Y'. Comparing for example chart 3 for the US and chart 4 which graph levels of US exports shares into others Executive Board members, we are able to distinguish between who the US

${ }^{7}$ Of course, the determinants of voting power index such as the weights, their distribution and the majority rule still play an important role in coalition building. But, it is not straightforward to identify what kind of determinants, ideological or numerical, play more, and moreover it is out of the scope of this paper. We consider that this is, however, an interesting path for future research. 
influence and by whom the US can be influenced. For example, we notice that the US could be very influential on a number of countries, such as Malaysia and India to pick two examples, but that only few countries may be influential on the US, which would include Canada or Venezuela.

\section{Chart A2.1: Repartition of export shares to EB members for the US and Germany}
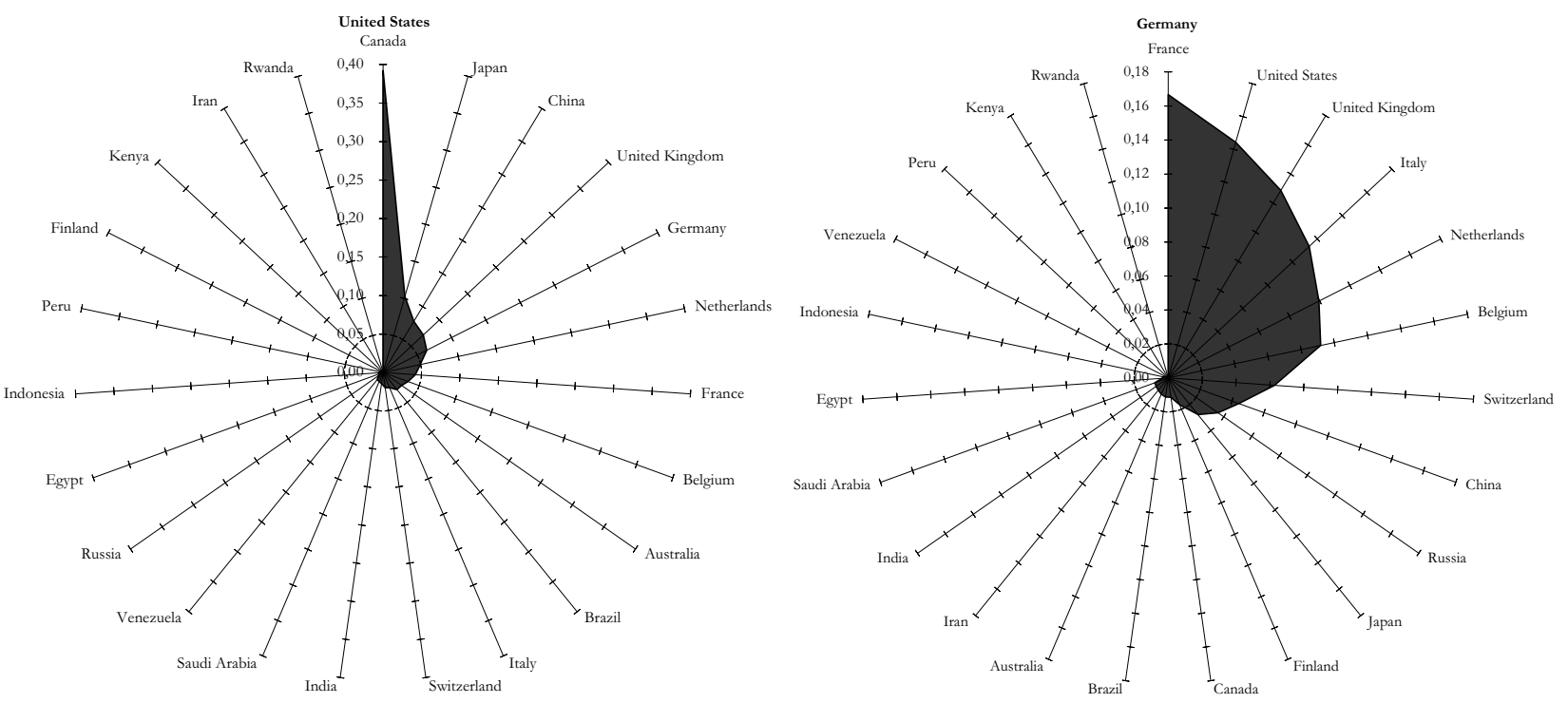

Chart A2.2: Repartition of US imports share by EB members

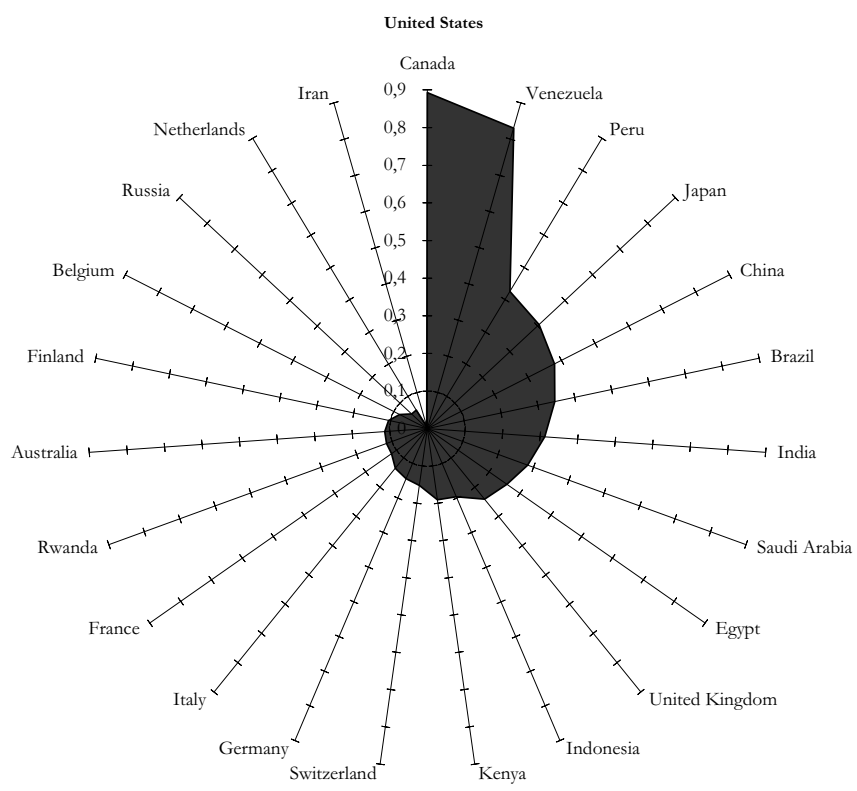

Source: IMF DOTS 


\section{European Central Bank Working Paper Series}

For a complete list of Working Papers published by the ECB, please visit the ECB's website (http://www.ecb.europa.eu)

773 "Exchange rate volatility and growth in small open economies at the EMU periphery" by G. Schnabl, July 2007.

774 "Shocks, structures or monetary policies? The euro area and US after 200I" by L. Christiano, R. Motto and M. Rostagno, July 2007.

775 "The dynamic behaviour of budget components and output" by A. Afonso and P. Claeys, July 2007.

776 "Insights gained from conversations with labor market decision makers" by T. F. Bewley, July 2007.

777 "Downward nominal wage rigidity in the OECD" by S. Holden and F. Wulfsberg, July 2007.

778 "Employment protection legislation and wages" by M. Leonardi and G. Pica, July 2007.

779 "On-the-job search and the cyclical dynamics of the labor market" by M. U. Krause and T. A. Lubik, July 2007.

780 "Dynamics and monetary policy in a fair wage model of the business cycle" by D. de la Croix, G. de Walque and R. Wouters, July 2007.

78I "Wage inequality in Spain: recent developments" by M. Izquierdo and A. Lacuesta, July 2007.

782 "Panel data estimates of the production function and product and labor market imperfections" by S. Dobbelaere and J. Mairesse, July 2007.

783 "The cyclicality of effective wages within employer-employee matches: evidence from German panel data" by S. Anger, July 2007.

784 "Understanding the dynamics of labor shares and inflation" by M. Lawless and K. Whelan, July 2007.

785 "Aggregating Phillips curves" by J. Imbs, E. Jondeau and F. Pelgrin, July 2007.

786 "The economic impact of merger control: what is special about banking?" by E. Carletti, P. Hartmann and S. Ongena, July 2007.

787 "Finance and growth: a macroeconomic assessment of the evidence from a European angle" by E. Papaioannou, July 2007.

788 "Evaluating the real effect of bank branching deregulation: comparing contiguous counties across U.S. state borders" by R. R. Huang, July 2007.

789 "Modeling the impact of external factors on the euro area's HICP and real economy: a focus on pass-through and the trade balance" by L. Landolfo, July 2007.

790 "Asset prices, exchange rates and the current account" by M. Fratzscher, L. Juvenal and L. Sarno, August 2007.

79| "Inquiries on dynamics of transition economy convergence in a two-country model" by J. Brůha and J. Podpiera, August 2007. 
792 "Euro area market reactions to the monetary developments press release" by J. Coffinet and S. Gouteron, August 2007.

793 "Structural econometric approach to bidding in the main refinancing operations of the Eurosystem" by N. Cassola, C. Ewerhart and C. Morana, August 2007.

794 "(Un)naturally low? Sequential Monte Carlo tracking of the US natural interest rate" by M. J. Lombardi and S. Sgherri, August 2007.

795 "Assessing the impact of a change in the composition of public spending: a DSGE approach" by R. Straub and I. Tchakarov, August 2007.

796 "The impact of exchange rate shocks on sectoral activity and prices in the euro area" by E. Hahn, August 2007.

797 "Joint estimation of the natural rate of interest, the natural rate of unemployment, expected inflation, and potential output" by L. Benati and G. Vitale, August 2007.

798 "The transmission of US cyclical developments to the rest of the world" by S. Dées and I. Vansteenkiste, August 2007.

799 "Monetary policy shocks in a two-sector open economy: an empirical study" by R. Llaudes, August 2007.

800 "Is the corporate bond market forward looking?" by J. Hilscher, August 2007.

801 "Uncovered interest parity at distant horizons: evidence on emerging economies \& nonlinearities" by A. Mehl and L. Cappiello, August 2007.

802 "Investigating time-variation in the marginal predictive power of the yield spread" by L. Benati and C. Goodhart, August 2007.

803 "Optimal monetary policy in an estimated DSGE for the euro area" by S. Adjemian, M. Darracq Pariès and S. Moyen, August 2007.

804 "Growth accounting for the euro area: a structural approach" by T. Proietti and A. Musso, August 2007.

805 "The pricing of risk in European credit and corporate bond markets" by A. Berndt and I. Obreja, August 2007.

806 "State-dependency and firm-level optimization: a contribution to Calvo price staggering" by P. McAdam and A. Willman, August 2007.

807 "Cross-border lending contagion in multinational banks" by A. Derviz and J. Podpiera, September 2007.

808 "Model misspecification, the equilibrium natural interest rate and the equity premium" by $\mathrm{O}$. Tristani, September 2007.

809 "Is the New Keynesian Phillips curve flat?" by K. Kuester, G. J. Müller and S. Stölting, September 2007.

810 "Inflation persistence: euro area and new EU Member States" by M. Franta, B. Saxa and K. Šmídková, September 2007.

81I "Instability and nonlinearity in the euro area Phillips curve" by A. Musso, L. Stracca and D. van Dijk, September 2007.

812 "The uncovered return parity condition" by L. Cappiello and R. A. De Santis, September 2007. 
813 "The role of the exchange rate for adjustment in boom and bust episodes" by R. Martin, L. Schuknecht and I. Vansteenkiste, September 2007.

814 "Choice of currency in bond issuance and the international role of currencies" by N. Siegfried, E. Simeonova and C. Vespro, September 2007.

815 "Do international portfolio investors follow firms' foreign investment decisions?" by R. A. De Santis and P. Ehling, September 2007.

816 "The role of credit aggregates and asset prices in the transmission mechanism: a comparison between the euro area and the US" by S. Kaufmann and M. T. Valderrama, September 2007.

817 "Convergence and anchoring of yield curves in the euro area" by M. Ehrmann, M. Fratzscher, R. S. Gürkaynak and E. T. Swanson, October 2007.

818 “Is time ripe for price level path stability?" by V. Gaspar, F. Smets and D. Vestin, October 2007.

819 "Proximity and linkages among coalition participants: a new voting power measure applied to the International Monetary Fund" by J. Reynaud, C. Thimann and L. Gatarek, October 2007. 


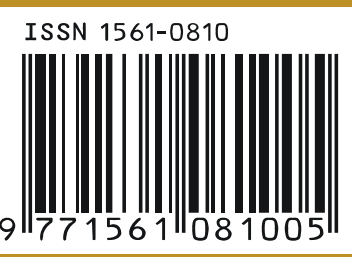

